\title{
Introducción al dossier
}

\section{Obispos y obispados en la Antigüedad Tardía y la Edad Media: jerarquías y estrategias de acción}

\author{
Mariel Pérez y Andrea V. Neyra
}

El dossier que presentamos tiene su origen en el Encuentro de Actualización y Discusión "Obispos y obispados en la Antigüedad Tardia y la Edad Media. Jerarquías y estrategias de acción", llevado a cabo en el Instituto de Historia Antigua y Medieval "José Luis Romero" los días 26 y 27 de junio de 2018. En dicha ocasión, convocamos a presentar ponencias orientadas a reflexionar sobre el rol del obispo en la Antigüedad Tardía y la Edad Media a partir del abordaje específico de problemáticas relacionadas con las estrategias de construcción de poder y distinción social que este desplegaba en el seno de las diversas constelaciones sociales, políticas e institucionales en las que se situaba. Desde este punto de partida, se apuntaba a promover un diálogo entre miradas diversas, trascendiendo las compartimentaciones temporales y espaciales así como las fronteras disciplinarias, teóricas y metodológicas.

La atención sobre la figura episcopal, sus funciones, marcos de acción, orígenes y extracción social han sido el centro de una vasta producción historiográfica. En las últimas décadas el interés se ha renovado en base a miradas que impulsan una perspectiva más dinámica de las relaciones en las que el obispo se encontraba inserto, de modo que este es entendido desde su individualidad dentro de un marco más general y como un agente activo en la construcción tanto del rol específico como del ejercicio concreto del poder episcopal puesto de manifiesto en casos particulares. Estudios y cuestionamientos como aquellos desarrollados en "The 'Imperial Church System' of the Ottonian and Salian Rulers: a Reconsideration" (Reuter, 1982:347-374) de Timothy Reuter para el área de Europa central han promovido la revisión de los conceptos y abordajes acerca del obispo como un actor social significativo en la configuración del mundo medieval. Por otra parte, en los últimos años el estudio del obispo medieval se ha orientado hacia nuevas problemáticas, abriendo fecundas líneas de investigación dentro de ámbitos historiográficos diversos. En este sentido, debe señalarse el visible interés por el estudio de cuestiones como la complejidad del oficio episcopal, la naturaleza del poder episcopal y su ejercicio, las representaciones de la figura del obispo en diferentes registros, las multifacéticas y cambiantes relaciones del obispo con los poderes laicos y con otros sectores de la Iglesia, o las formas en que su poder se inscribía en el espacio. ${ }^{1}$

En este marco, los siete artículos que se incluyen en el presente dossier ponen al obispo en el centro de la reflexión pero a partir de análisis de casos enfocados en distintos escenarios, tanto desde el punto de vista geográfico-temporal como social y político: la Galia tardoantigua, la Italia ostrogoda, el reino visigodo, el Imperio otoniano, la España medieval y el Imperio Bizantino. Estos trabajos exploran, a su vez,
1. Ilustran este mosaico de enfoques en relación con la figura episcopal en las últimas décadas, Palazzo (1999), Aurell y García de la Borbolla (2004), Trumbore Jones y Ott (2007), Trumbore Jones (2009), Körntgen y Waßenhoven (2011), García de Cortázar y Teja (2013), Ott (2015), Mazel (2016), entre otros. 
una diversidad de perspectivas de abordaje apelando al análisis de distintos registros y géneros documentales diversos. No obstante, en esta heterogeneidad pueden distinguirse líneas de convergencia, como el énfasis en la agencia de los actores y en su inscripción en redes de relaciones que exceden la mera organización eclesiástica, la búsqueda de una articulación entre las coyunturas específicas y los contextos sociales, políticos e institucionales más amplios, o la consideración de los márgenes de acción posibles dentro de dichas coyunturas.

Los artículos de Liliana Pégolo, Estefanía Sottocorno, Dolores Castro y Eleonora Dell'Elicine enfocan la mirada en el obispo tardoantiguo procurando comprender su obra y sus prácticas dentro de las coordenadas políticas, eclesiásticas y propiamente intelectuales de su tiempo. Liliana Pégolo se centra en el escritor Venancio Fortunato, una figura de la transición de la sociedad tardoantigua hacia la medieval, de la que da cuenta su obra. Este novus Orpheus, como lo denomina la autora haciéndose eco de la identificación del propio Venancio Fortunato, estableció relaciones con altos dignatarios seculares y eclesiásticos, dentro de los cuales destacan los obispos Leoncio de Bordeaux, Félix de Nantes y Gregorio de Tours para quienes redactó dossiers de composiciones. La obra literaria de este oriundo del Véneto nos ofrece una mirada no solo acerca de sus vínculos de amicitia con los círculos de poder, sino también acerca de la auctoritas episcopal enmarcada en el juego de relaciones con los grupos de poder local. Por su parte, Estefanía Sottocorno se dedica a analizar la influencia agustiniana sobre la producción literaria de miembros de la élite letrada romana que se encontraban al servicio de la corte ostrogoda. La autora se pregunta particularmente acerca de la recepción de la soteriología del Hiponense en la obra de Cesáreo de Arles, Ennodio de Pavía, Boecio y Casiodoro, en un marco dado por los cuestionamientos a la autoridad de Agustín y las elaboraciones dogmáticas que se desarrollaban al respecto en centros monásticos del sur de la Galia y del norte de África.

Con foco en el reino visigodo, Dolores Castro examina las estrategias y procedimientos que desplegaron los obispos visigodos -en particular, Isidoro de Sevilla, Ildefonso de Toledo y Julián de Toledo- para dar un marco cristiano de referencia e identidad al reino visigodo al tiempo que afirmaban a la jerarquía eclesiástica como la voz autorizada para interpretar y enseñar el mensaje revelado. La autora enfatiza el papel activo que en este sentido desempeñaron los obispos, cuyo accionar no supuso una mera reproducción de los enunciados de la tradición bíblico-patrística, sino un trabajo de selección, organización y adaptación de esos contenidos en función de intereses y preocupaciones específicos, vinculados con necesidades concretas del mundo visigodo del siglo VII. En un mismo escenario pero en otro plano de análisis y recurriendo a fuentes de carácter jurídico, el artículo de Eleonora Dell'Elicine explora las estrategias desplegadas los obispos en relación con la administración de los bienes de la Iglesia en el ámbito de la diócesis. La autora sitúa al obispo en el centro de una competencia social y política en la que se destacaban dos actores: la jerarquía eclesiástica y la monarquía. En ese marco, se analiza cómo operaba el obispo en la tensión entre la legislación y la competencia facciosa.

El artículo de Andrea Vanina Neyra cambia el eje espacio-temporal para adentrarse en la concepción y el ejercicio del poder episcopal en la era otoniana. El análisis del obispo y cronista Thietmar de Merseburg nos acerca a un exponente que no solo desarrolló la tarea, sino que a la vez reflexionó acerca del estatus y rol de sus colegas. Concebida como una actividad con una fuerte impronta administrativa a la vez que pastoral, Thietmar consideraba que el ejercicio del poder episcopal se encontraba influido por la inserción en una red de poder caracterizada por las tensiones entre las obligaciones seculares y espirituales, mientras proponía una actuación moderada y atenta a las necesidades de la diócesis por parte de los obispos. Las acciones concretas de aquellos -virtuosas o reprobables- modelaban el oficio. 
Mariel Pérez se sumerge en la dinámica de construcción del poder episcopal en la España medieval, poniendo el foco de atención en la competencia entre obispados y centros monásticos. A través del análisis de las disputas que enfrentaron a los obispos de León con el monasterio de Sahagún entre fines del siglo XI y principios de XIII, la autora expone las dificultades a las que se enfrentaron los obispos para desplegar su jurisdicción sobre las iglesias de la diócesis frente a los efectos disolventes que ejercían los monasterios e identifica las estrategias que favorecieron la implantación del poder episcopal dentro del espacio diocesano. Este desarrollo, a su vez, implica una reflexión sobre la diócesis como ámbito territorial en el que se inscribe la jurisdicción del obispo, que en este marco se presenta como un espacio discontinuo, heterogéneo y disputado que se hallaba aún en proceso de construcción.

Finalmente, Victoria Casamiquela Gerhold desplaza la mirada hacia el Imperio Bizantino, examinando las complejas relaciones entre el poder imperial y la Iglesia de Constantinopla durante el período de los Comnenos. Su trabajo muestra que estas relaciones estuvieron fuertemente marcadas por la situación interna de la Iglesia, signada por la competencia facciosa entre distintos sectores para consolidar su poder dentro de la institución eclesiástica y afirmar su posición frente al poder imperial. Así, si la alianza entre el poder imperial y la administración patriarcal impulsada por Alexis I Comneno resultó fructífera en un contexto de inestabilidad política, en el largo plazo se habría demostrado frágil, vulnerable al conflictivo juego de intereses tejido en el seno de la Iglesia.

La compilación de trabajos que se recoge en las páginas que siguen pretende contribuir a la continuidad de las discusiones y replanteos en torno a un personaje, el obispo, y sus ámbitos de acción, que, si bien tienen en el obispado su núcleo definitorio, se despliegan en múltiples planos penetrando dentro de las jerarquías eclesiásticas y seculares y dentro de las redes de poder tejidas a escala local y supralocal. A través del estudio de casos diversos, inscriptos en marcos geográficos y temporales disímiles, se busca repensar desde una perspectiva transversal los roles, prácticas y representaciones del obispo en su contexto, moldeados por las coyunturas y redes de relaciones en las que actuaban. De este modo, consideramos que abrimos un espacio fecundo para el debate y la reflexión acerca de las dinámicas propias de la sociedad tardoantigua y medieval a partir del análisis, a coro con las tendencias académicas recientes sobre el tema de estudio, de uno de sus actores sociales más significativos. 


\section{Q Bibliografía}

》Aurell, M. y García de la Borbolla, A. (eds.) (2004). La imagen del obispo hispano en la Edad Media, Eunsa, Barañáin.

" García de Cortázar, J. Á. y Teja, R. (coord.) (2013). Monjes y obispos en la España del románico: entre la connivencia y el conflicto, Fundación Santa María la Real, Palencia.

" Körntgen, L. y Waßenhoven, D. (eds.) (2011). Patterns of Episcopal Power. Bishops in Tenth and Eleventh Century Western Europe, De Gruyter, Berlin-Boston.

» Mazel, F. (2016). L'évêque et le territoire. L'invention médiévale de l'espace (Ve-XIlle siècle), Seuil, Paris.

»Ott, J. S. (2015). Bishops, Authority and Community in Northwestern Europe, c.1050-1150, Cambridge University Press, Cambridge.

»Palazzo, E. (1999). L'évêque et son image: l'illustration du Pontifical au Moyen Age, Brepols, Turnhout.

» Reuter, T. (1982). “The 'Imperial Church System' of the Ottonian and Salian Rulers: a Reconsideration", The Journal of Ecclesiastical History, 33, pp. 347-374.

"Trumbore Jones, A. (2009). Noble Lord, Good Shepherd: Episcopal Power and Piety in Aquitaine, 877-1050, Brill, Leiden.

»Trumbore Jones, A. y Ott, J. S. (ed.) (2007). The bishop reformed: studies of episcopal power and culture in the central Middle Ages, Ashgate, Aldershot. 